\title{
O gênero micronarrativa em contexto digital pela perspectiva do Interacionismo Sociodiscursivo
}

\author{
El género minificción en contexto digital desde la \\ perspectiva del Interaccionismo Sociodiscursivo
}

\author{
The short short story in digital context from the perspective \\ of Sociodiscursive Interactionism
}

\author{
Larissa Sigulo Freire ${ }^{1}$
}

\begin{abstract}
RESUMO: A micronarrativa, gênero próprio da contemporaneidade, é composta por enunciados curtos em sua materialidade, mas ricos em efeitos de sentido, o que possibilita que se possa investigar as relações humanas a partir dos discursos nela permeados. Para que essa investigação ocorra, utilizaremos o aporte teórico do Interacionismo Sociodiscursivo, ao compreender que ele abarca os desdobramentos discursivos que esse gênero pode tomar, entendendo o humano como ser psicológico, social e histórico. Como corpus, foram selecionados textos advindos da Internet, em que é possível revelar o caráter hodierno desse gênero, uma vez que sua divulgação se dá em ambiente digital, como fruto das transformações comunicacionais do fim do século XX e o século XXI.
\end{abstract}

PALAVRAS-CHAVE: Micronarrativa. Ciberespaço. Socio-histórico. ISD.

RESUMEN: La minificción, género propio de la contemporaneidad, tiene como parte de sus configuraciones un teor altamente actual y la velocidad de la comunicación humana en la Era de la información. Está compuesta por cortos enunciados en su materialidad, pero ricos en efectos de sentido, lo que da la posibilidad de investigar las relaciones humanas a partir de sus recursos. Para que ocurra esta investigación, utilizaremos del aporte teórico "Interacionismo Sociodiscursivo", al comprender que abarca desdoblamientos discursivos que puede tomar el género, entendiendo al humano como ser psicológico, social e histórico. Como "corpus", fueron seleccionados textos del

1 Doutoranda do Programa de Pós-Graduação em Estudos da Linguagem da Universidade Estadual de Londrina e Mestra pelo mesmo programa. Realiza pesquisa que envolve os discursos digitais e seus efeitos de sentido em perspectiva discursiva. Endereço eletrônico para contato: larissasigulo@hotmail.com. 
internet, donde es posible identificar el carácter actual de este género, una vez que su divulgación se da en un medio digital, como fruto de las transformaciones comunicacionales del fin del século XX y século XXI.

PALABRAS CLAVE: Minificción. Ciberespacio. Sociohistórico. ISD.

ABSTRACT: The short short story, the genre of contemporaneity, shows its fast and modern face as part of the social configurations in the Information Age. It is composed of short statements in its materiality, but rich in meaning effects, which makes it possible to investigate human relations from the discourses contained in it. For this research to occur, we will use the theoretical contribution of Sociodiscursive Interactionism, understanding that it encompasses the discursive unfolding that this genre can take, comprehending humans as psychological, social and historical beings. As our corpus, texts derived from the Internet were selected, in which it is possible to reveal the current character of this genre, since its dissemination occurs in a digital environment, as a result of the communication transformations of the end of the twentieth century and the twenty-first century.

KEYWORDS: Short short story. Cyberspace. Socio-historical. SDI.

\section{Introdução}

$\mathrm{Na}$ direção das mudanças tecnológicas dos últimos tempos, a micronarrativa ${ }^{2}$ pode ser vista como um gênero que não depende da internet para sobreviver, na verdade surgiu bem antes dela, mas encontrou no ambiente digital um solo fértil para a sua produção. É breve, fluida e profunda, como um projétil de alto calibre. Perfura as mais calcadas camadas do imaginário humano, ativando operações mentais capazes de dar sentido complexo a poucas linhas.

Para acomodar tal dinamicidade e dar conta de analisar um corpus tão significativo, ainda que muito curto, apenas uma teoria que abarca as várias facetas do conhecimento humano sob uma mesma bandeira, o Interacionismo

\footnotetext{
${ }^{2} \mathrm{O}$ termo micronarrativa equivale a outros termos correlatos: microconto, miniconto, microficção, que não representam consenso em seu uso, tanto por autores literários quanto por teóricos. A escolha de "micronarrativa" especificamente ocorreu porque entendemos que o gênero independe de uma possível categorização do gênero conto, mas se configura como seu próprio fenômeno de comunicação, esse que possui as estruturas narrativas, ainda que extremamente reduzidas. Na américa espanhola o gênero é conhecido como minificción, micro-relato e ficción mínima. Em inglês, pode ser traduzido como microfiction, very short story, short short storye outros (VIEIRA, 2012, p. 18).
} 
Sociodiscursivo. Por trabalhar com o discurso, essa corrente teórica considera fatores externos ao texto que proporcionam ao indivíduo a possibilidade de imprimir em sua produção suas intencionalidades, semiotizações e representações do mundo fisíco e sociosubjetivo (HABERMAS apud BRONCKART, 2003, p. 77), e será a base pela qual fundamentaremos nossas análises.

\section{Breves considerações sobre micronarrativa, ciberespaço e cibercultura}

A micronarrativa é um gênero que tem uma capacidade ímpar de revelar as mudanças comunicativas da Era da Informação. Sendo um gênero que encontra solo fértil na internet, ela revela essa nova face da comunicação humana que acontece nas mídias digitais e que pede por fluidez e brevidade.

O microconto não é gentil. Não tem a compaixão do romance ou a simpatia do conto. Não oferece filme ou foto. Exige. É o leitor quem começa, termina ou, simplesmente, aceita a história. Assim se faz, no Brasil, a literatura que surge na interface com a internet na primeira década do século XXI (SOUZA; RODRIGUES, 2011, p. 270).

O que Souza e Rodrigues propõem é que se pode discutir a socio-história da micronarrativa e levantar possibilidades para explicar seu surgimento, mas não se deve negar que esse gênero é produto da contemporaneidade. E quando o colocamos em uma perspectiva discursiva, ou seja, analisando os discursos por tudo o que os compõe - aspectos linguísticos, ideológicos, históricos e subjetivos -, observamos que os enunciados produzidos nas condições atuais possuem as marcas das mudanças sociais ocorridas no último século. Como se pode, então, definir a micronarrativa? Pode-se buscar uma abordagem objetiva, como propõe Lagmanovich (2011, p. 4), o qual estabelece que a micronarrativa (microrrelato e miniconto, para o autor) se refere a enunciados muito breves, que carregam o teor narrativo e ficcional. 
Em nossa caracterização geral do microrrelato consideramos eminentemente a brevidade, e também defendemos outro aspecto, 0 da narratividade (ou seja, não há microrrelato se não se conta algo). [...] Mas há um terceiro aspecto do miniconto que também é preciso levar em conta: seu caráter ficcional (LAGMANOVICH, 2011, p. 4, tradução nossa).

Mas quão breve devem ser esses textos? Zavala (2000, p. 50) estabelece o limite de uma página. Marcelino Freire, ao propor sua coletânea de "microcontos", optou por 50 letras. No ciberespaço, há narrativas que variam de tamanho, pois dependem da plataforma em que estão publicadas: se estão em redes sociais com limites de caracteres, como o Twitter - com seus recentes 280 caracteres - esse limite deve ser respeitado; contudo, alcançam outras dimensões em blogs e sites específicos. Dessa forma, falar da estrutura apenas se mostra insuficiente.

A micronarrativa configura-se como um enunciado que, apesar de materialmente breve, discursivamente nunca o será, uma vez que os discursos são uma construção dinâmica de sentidos, que se tornam possível pela mobilização de estratégias mentais do indivíduo e seus marcadores sociais. Assim, o gênero micronarrativa é composto por enunciados que se propõem narrativos ao instigar no sujeito leitor o resgate de seus conhecimentos prévios, acessando dizeres outros, participantes estes da construção da noção que se tem sobre narratividade e ficcionalidade

Partindo dessa visão quase abstrata sobre a estrutura do gênero, podemos perceber que ela muito bem combina com a fluidez das redes. É difícil, portanto, definir o que é o ciberespaço com a intenção de firmar limites para sua atuação, isso porque, nos dias de hoje, uma vida alheia à influência das mídias digitais é potencialmente inimaginável. Havendo o desejo de se alienar em relação a elas, o indivíduo evitará o uso de computadores, celulares de alta tecnologia ou qualquer outro contato que eventualmente fará com a internet. Esse empreendimento seria bem-sucedido se as pessoas fossem capazes do isolamento total, da completa exclusão do outro em suas práticas. Bem sabemos 
que o homem é um ser social e interativo em sua essência, pois a linguagem é social, e nos criamos enquanto seres pensantes e atuantes justamente por ela. Assim, tal afastamento, ainda que aparentemente possível em algumas ocasiões, não faz parte do que somos enquanto humanos, perpassados pela linguagem e orientados ideologicamente.

Carregamos nossas atividades corriqueiras em servidores e compartilhamos informações a todo segundo. As novas tecnologias guiam nossa interação com o mundo, desde operações bancárias até conversas informais, passando pela arte, pela política e pelo crime. Os meios pelos quais nos comunicamos agora abarcam novos suportes, e as mídias digitais estão no centro dessas novas formas de comunicação. Isso quer dizer que "Seres humanos continuam sendo seres humanos, em toda sua paradoxal complexidade, mas conectados de uma maneira diferente a partir das mídias digitais" (MARTINO, 2014, p. 10).

Essa "maneira diferente" de nos conectarmos é recente, produto das mudanças políticas e econômicas ocorridas ao longo do século XX, tendo seu momento ideal no século XXI, quando a internet passou a ser ferramenta essencial nos lares e espaços de trabalho mundo a fora. Nesse sentido, fazemos parte de uma sociedade globalizada, ou seja, acostumada à troca de informações, à disponibilidade de conhecimentos compartilhados pelas comunidades virtuais, que representam, a cada dia, a regra geral das interações sociais.

Quando os sujeitos se conectam a dispositivos digitais - computadores, celulares, tablets -, eles adentram no ciberespaço. Quando participam do processo de produção de informações, eles começam a fazer parte da cibercultura. O ciberespaço é o "ambiente digital" criado pela relação entre dispositivos digitais e seus usuários.

Se o ciberespaço é "ambiente", a cibercultura é tudo o que "se faz nesse ambiente". Ou seja, depois de nos conectarmos a um dispositivo digital, começamos a interagir com ele e com os outros por meio dela, seja por trocar mensagens com um amigo, ler as notícias do dia, ou postar em uma rede social. Entretextos, Londrina, v. 19, n. 1 p. 193- 206 Dossiê Temático/ 2019 
Todas essas ações e todos os discursos que emanam delas formam a cibercultura.

A cibercultura em alguns pontos carrega características das culturas do "mundo físico", como aponta Martino (2014, p. 50). Para ele, há a migração daquilo que se produz no mundo físico para o mundo virtual, onde ocorre uma série de transformações capazes de tornar as culturas irreconhecíveis. Ou seja, o ciberespaço com suas estruturas oferece condições próprias de produção dos discursos e dos sentidos. É nesse ponto que a globalização se manifesta de modo mais.

Os textos produzidos no ciberespaço são, dessa forma, integrantes de um grande movimento de atualização das condições sociais, em que se estimula a integração entre os indivíduos da sociedade de forma intensa, integral e simultânea. Essa integração pode tanto causar a aproximação das pessoas quanto causar a criação de "bolsões", em que os interesses em comum "aprisionam" os sujeitos em bolhas ideológicas. De tempos em tempos, essas bolhas se chocam, ou seja, os sujeitos de diferentes mentalidades se digladiam.

A cibercultura reflete esses choques ao carregar discursos combativos, isto é, parte deles levam as barreiras sociais para o meio virtual e parte tenta quebrálas, tudo no mesmo espaço. Vemos isso ao nos deparamos com discursos de ódio e segregação. Podemos nos engajar tanto da defesa deles, reafirmando as intenções, ou no combate a eles.

Portanto, se no mundo físico passamos por pessoas que possuem exatamente o mesmo interesse que nós e nunca saberemos, no ciberespaço esse interesse nos une. O contrário também é válido, entramos em conflito facilmente, porque somos pessoas totalmente estranhas conectadas por alguma sensação de comunidade.

Chegamos assim à micronarrativa, que habita esse ambiente em que as práticas e produções são realizadas e recebidas com rapidez e intensidade. Quem se interessa por arte e literatura encontra quem as produz, e os rótulos do cânone são ofuscados - porém não perdidos - pela facilidade e satisfação dos encontros. 


\title{
O Interacionismo Sociodiscursivo como base teórica
}

Toda essa reflexão acerca do ciberespaço, da cibercultura e, principalmente, da micronarrativa como gênero discursivo, encontra abrigo no arcabouço teórico do Interacionismo Sociodiscursivo (doravante ISD). Essa integração se faz ideal, porque o ISD não se conforma como uma corrente apenas linguística, nem psicológica ou sociológica, mas constrói-se na ideia de se colocar como a "ciência do humano". É multifacetado e dinâmico, assim como o corpus selecionado para este estudo e seu suporte digital. Isso quer dizer que em vez da compartimentalização das ciências, o ISD buscar ser uma teoria que se compreende em união com os diversos campos do saber. Para isso, encontra na sociologia, na psicologia e na linguística ferramentas para formar suas bases teóricas.

Pode-se compreender, então, que:

\begin{abstract}
O Interacionismo Sociodiscursivo (ISD) inscreve-se no interacionismo social, posição epistemológica geral composta por diversas correntes da filosofia e das ciências humanas [...]. Tomando como central a historicidade do ser humano, o interacionismo social se interessa tanto por, no nível filogenético (desenvolvimento da espécie), compreender as condições sob as quais se desenvolveram formas particulares de organização social, quanto, no ontogenético (desenvolvimento do indivíduo), perceber de que modo se desenvolveram formas de interação de caráter semiótico (VEÇOSSI, 2014, p. 1).
\end{abstract}

Essa noção nos é relevante, principalmente, porque versa sobre o caráter social de ser humano sem deixar de lado o modo como ele se desenvolve capaz de apreender os processos da interação social. Ele, portanto, vê-se embrenhado no construir dos sentidos, uma vez que é dotado das ferramentas psicológicas e linguísticas para isso.

Outro fator de extrema relevância para os estudos do ISD, portanto para este trabalho, é a questão dos gêneros. Apoiado no que desenvolvia Bakhtin, o ISD partilha da noção de gênero discursivo não como formas específicas em que Entretextos, Londrina, v. 19, n. 1 p. 193- 206 Dossiê Temático/ 2019 
o falante tenta "fazer caber" seus textos, mas sim resultado do contexto de produção e que serve a uma finalidade. Isso quer dizer que a existência dos gêneros baseia toda a produção comunicacional e, em consequência, de textos e discursos. Como partes seres atuantes na comunicação, seres que fazem valer seus dispositivos psicológicos e linguísticos, empregando conhecimentos prévios, os indivíduos não possuem a necessidade de conscientemente classificar os gêneros conforme os discursos são proferidos. Isso porque essa capacidade de identificação é uma dessas operações mentais próprias do falante, que analisa em uma fração de segundo as funcionalidades daquele determinado discurso e avalia se ele é adequado ao contexto de produção ou não. A micronarrativa, por exemplo, é bem recebida e compreendida em um contexto em que se espera ou se aceita um texto curto e narrativo. Não seria apropriado, porém, que ela aparecesse ocupando a função de um sermão religioso, ou um discurso político.

Os gêneros se manifestam na conduta ou no diálogo reais mediante a existência de condições de aparecimento ou de enunciação. Um gênero de discurso é, portanto, o que funda, simbolicamente o mundo no qual se processa a atividade dos sujeitos. Só há gênero se há modos possíveis de dizer ou de fazer de forma diferente, de fazer outras escolhas (FAITA, 2004, p. 68).

Apreende-se então que as condições sócio-históricas instigam as expectativas dos sujeitos em relação aos gêneros e permitem que este ou aquele discurso emerja.

\section{Análise do corpus}

Após termos fundado as bases para a análise do corpus, com um panorama sobre a micronarrativa enquanto um gênero "adotado" pelo ciberespaço, partiremos para o texto a ser trabalhado.

A micronarrativa a ser analisada encontra-se na página de Samir Mesquita, autor e desenvolvedor da obra. 
Imagem 1 - Visão do site samirmesquita.com.br

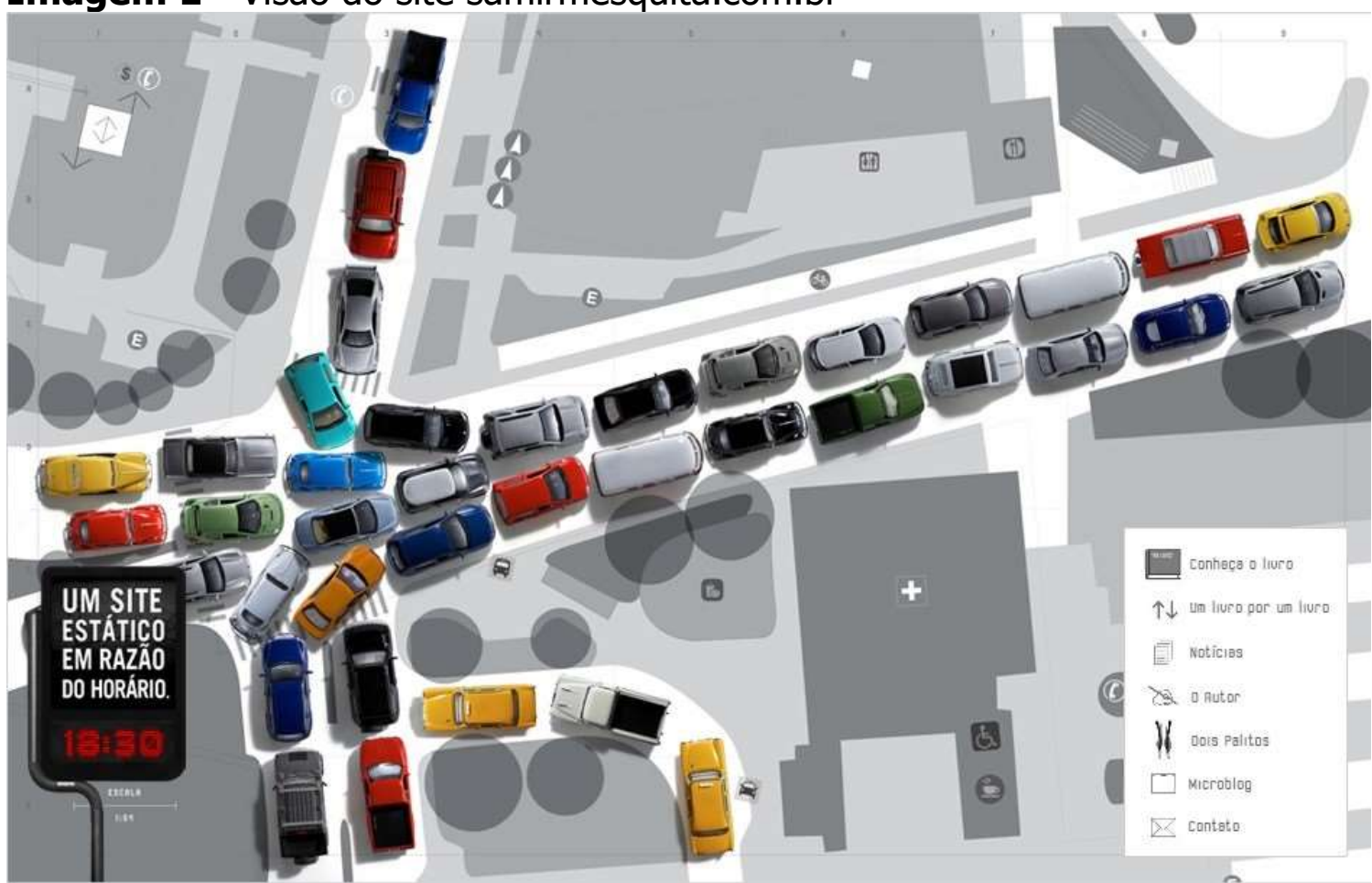

Fonte: Mesquita (2018).

O texto selecionado faz parte da obra interativa 18:30, que se apresenta como um cruzamento de ruas em que carros se aglomeram, sugerindo um trânsito parado. Como a placa no canto inferior esquerdo da imagem indica, a estaticidade do site e, consequentemente, dos carros se dá "em razão do horário". Ele faz referência ao fato de as figuras de carros estarem paradas e quem realiza o movimento da interação é o próprio leitor. Ele escolhe uma das figuras e clica nela, revelando um microtexto ficcional dentro da temática da vida nas cidades e em suas ruas. Ou seja, ainda que as micronarrativas tratem de relacionamentos, trabalho ou vida cotidiana, ainda assim farão referência ao contexto de trânsito congestionado das $18 \mathrm{~h} 30$ sugerido pela imagem.

A captação da obra em sua forma estática não consegue dar conta de toda a experiência que se tem ao se acessar o endereço eletrônico. Clicar nos carros dá a sensação de invadir o espaço privado dos sujeitos e cria a "liberdade" de explorar as narrativas na ordem que se deseja. Essa atmosfera ajuda o sujeito leitor a entrar em contato com seus conhecimentos prévios e resgatar dizeres e Entretextos, Londrina, v. 19, n. 1 p. 193- 206 Dossiê Temático/ 2019 
saberes já calcados na memória a respeito da temática "trânsito", facilitando a apreensão de sentidos que possivelmente emergirão nos discursos. Observemos a micronarrativa selecionada: "Câncer, o doutor disse. 90 dias no máximo. Mas já estava em ponto morto."

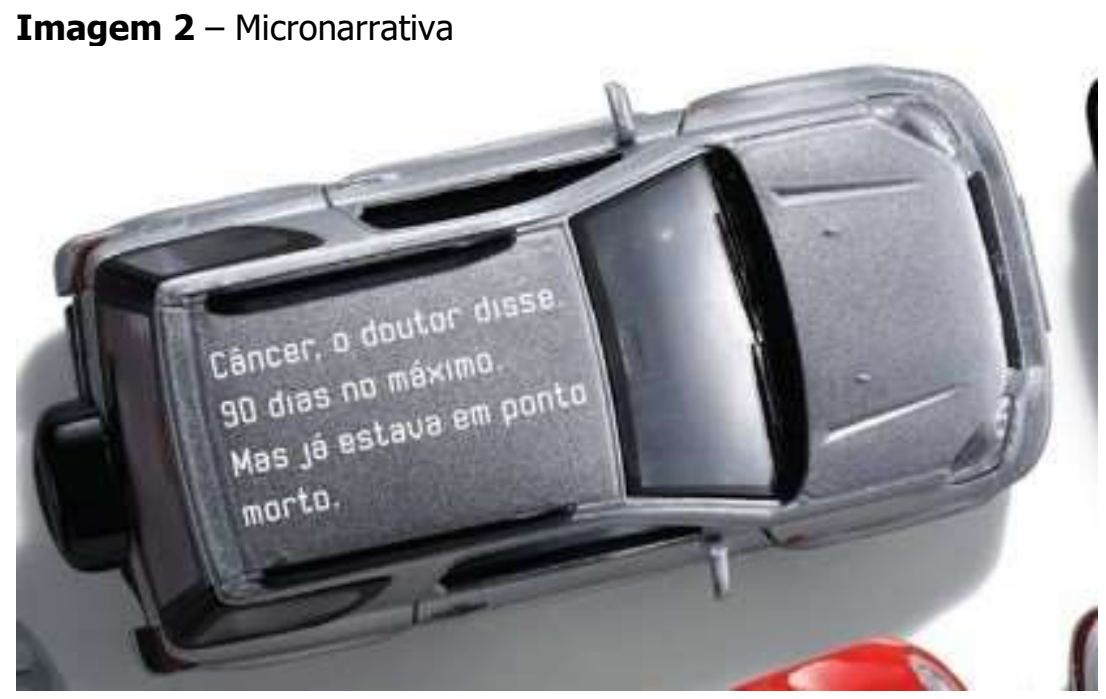

Fonte: Mesquita (2018).

Uma leitura possível do texto remete ao desejo de fazer uma crítica à vida monótona e inerte que se leva nos dias de hoje, em especial, nas grandes cidades.

Podemos apontar, na materialidade linguística, parte fundamental na emergência dos discursos, o efeito obtido ao se utilizar do discurso direto não marcado. "Câncer" e "90 dias no máximo" representam a fala de uma personagem que traz más notícias. É relevante observarmos a falta de uma marcação de discurso direto, seja por travessão ou aspas, pois isso garante uma certa fluidez e dinamicidade ao narrar, próprias do gênero micronarrativa.

Do conhecimento prévio, a ideia de que quem recebe uma notícia de morte, geralmente, sai de um estado de normalidade para os sentimentos de choque e tristeza é a que mais salta aos olhos. Mas o que ocorre neste caso é a quebra da expectativa, pois o texto revela a total apatia diante do infortúnio, uma 
vez que a tristeza e a depreciação pela vida já existiam, ideia trazida pela expressão "ponto morto".

Aqui é imperativo retomar o conceito de contexto de produção, pois é apenas por meio dele que se pode inferir quais são os significados mobilizados pela micronarrativa. Segundo Bronckart (2003, p. 93), contexto de produção "pode ser definido como o conjunto dos parâmetros que podem exercer uma influência sobre a forma como um texto é organizado". O autor fundou esse conceito na ideia de que um texto não se basta por si só, ele é não só influenciado, mas permitido e motivado pelos diversos fatores externos a ele. Assim se constrói o discurso, pela integração entre texto e contexto, entre o texto e sua exterioridade. Do mesmo modo como o autor imprime essa exterioridade em sua produção, o leitor apreende, se não tudo, aquilo que sua própria constituição enquanto sujeito permite. É um jogo entre sujeitos e suas atribuições sócio-históricas.

Dentro da cena automobilística - externa ao texto, mas participante do discurso -, na qual a imagem contextualizadora situa os dizeres, a expressão "ponto morto" representa a não aceleração ou o não funcionamento do motor de um carro. Ou seja, o automóvel se locomove ao sabor das forças externas que operam sobre ele e não por sua própria ação. No resgate dessa noção, atrelamse a doença e a morte, e tem-se um sujeito vítima da inércia da sua vida, sem ter e sem querer ter o controle sobre ela, e isso já acontecia independentemente do prognóstico negativo de sua doença.

Podemos, dessa forma, pensar em como esses sentimentos pesam na configuração da sociedade atual, que mesmo conectada a redes sociais, onde é estimulada a compartilhar, curtir, comentar e adicionar, não consegue ter esse mesmo senso de realização no mundo físico.

Temos assim que a exterioridade do texto em questão aponta para uma época em que a palavra-chave é mudança. A sociedade sempre mudou, evoluiu, mas nesta época a mudança é veloz, e tem de ser veloz, especialmente com relação ao modo de se conectar um ao outro. As atuais gerações, acostumadas Entretextos, Londrina, v. 19, n. 1 p. 193- 206 Dossiê Temático/ 2019 
com a fluidez da vida na internet, em banda larga, espera movimentos rápidos. Essa leitura só é possível pois levamos em consideração a exterioridade textual, as condições de produção e as informações constitutivas do conteúdo temático, representado por Bronckart (2003, p. 97).

\begin{abstract}
Assim como os parâmetros do contexto, as informações constitutivas do conteúdo temático são representações construídas pelo agente produtor. Trata- se de conhecimentos que variam em função da experiência e do nível de desenvolvimento do agente e que estão estocados e organizados em sua memória, previamente, antes do desencadear da ação de linguagem.
\end{abstract}

A globalização, ou seja, a abstração de fronteiras que separem as pessoas e impeça a circulação de informação, apoiada pelas mídias digitais, dita nossas ações e dizeres e modifica como atuamos enquanto sociedade, seja online ou não. Isso quer dizer que por mais motivados que os sujeitos se sintam a se conectarem com outros no meio digital, essa conexão pode não ocorrer fora dele. A vida em comunidade mudou, por conta da emergência das mídias digitais, mas também pela migração massiva para as cidades, que, cada vez maiores, blinda seus habitantes com concreto e aço, em seus apartamentos e automóveis. Isso traz os sentimentos de apatia e pessimismo, vindos do isolamento que insatisfaz os sujeitos. Esse pensamento de solidão perturba justamente pelo que já foi apontado neste trabalho, pela natureza social dos indivíduos, que só se constituem como agentes, atuantes, se estiverem em sociedade, como anuncia Vygostsky (1997, p. 38) "A vida social é um processo dinâmico, onde cada sujeito é ativo e onde acontece a interação entre o mundo cultural e o mundo subjetivo de cada um".

$O$ século $X X$ trouxe intensas mudanças sociais e políticas, e isso faz parte dos sentidos que apreendemos nos discursos da micronarrativa, pois o discurso não é senão a articulação de aspectos linguísticos com os extralinguísticos. Só podemos pensar em como uma pessoa em "ponto morto" se sente, se pensarmos 
em quanto a sociedade age nesse determinado momento histórico, em sua configuração espaço-temporal.

\section{Considerações Finais}

Diante da atual configuração social da Era Tecnológica, então, e pautados pelos conceitos levantados pelo ISD, como gênero e contexto de produção, pudemos perceber a micronarrativa como produto de seu tempo. Repleta de padrões sociais, seus textos revelam a possibilidade de enxergar o homem como ser social, perpassado pela linguagem e constrangido por ideologias. São seus aspectos sócio-históricos que ditam aquilo que ele poderá ou não dizer, também o que deverá apreender dos discursos.

Isso é de suma relevância porque confirma a aplicação do ISD como teoria viva, ou seja, que observa a configuração humana e a estuda com clareza ímpar. Ao declarar-se uma "ciência do humano", como postulado por Bronckart, o ISD se permite transitar pelas muitas faces e capacidades do homem, admitindo sua complexa natureza. Complexos também são seus exercícios mentais, os quais não são visíveis, mas significam, na tessitura textual.

Por isso, ainda que breve, a micronarrativa se faz um campo propício para os desvelamentos da capacidade humana de criar e compreender. Ainda que brevíssimos, os textos do gênero permitem uma análise ampla, justamente por mover conhecimentos prévios dos sujeitos, mas acessados no momento da enunciação, que não se limitam a sua materialidade, muito pelo contrário, extrapolam os limites do texto e transformam os indivíduos em sujeitos do agir.

\section{Referências}

BRONCKART, Jean Paul. As condições de produção dos textos. In: BRONCKART, Jean Paul. Atividade de linguagem, textos e discursos. por um sócioInteracionismo-discursivo. Tradução de Anna Rachel Machado, Péricles Cunha. São Paulo: EDUC, 2003. p. 91-110. 
FAITA, Daniel. Gêneros de discurso, gêneros de atividade, análise da atividade do Professor. In: MACHADO, Anna Rachel (org.). O ensino como trabalho. uma abordagem discursiva. Londrina: EDUEL, 2004. p. 53-80.

LAGMANOVICH, David. En el territorio de los microtextos. El Cuento em Red: Revista Electrónica Teoría de la Ficción Breve, Ciudad do México, DF, n. 23, primavera, p. 3-8, 2011.

MARTINO, Luís Mauro Sá. Teoria das mídias digitais. linguagens, ambientes e redes. Petrópolis: Editora Vozes, 2014.

MESQUITA, Samir. 18:30. Disponível em: http://samirmesquita.com.br. Acesso em: 24 out. 2018.

SOUZA, Fabrina Martinez de; RODRIGUES, Rauer Ribeiro. Uma introdução historiográfica ao estudo do microconto brasileiro. Carandá: Revista do Curso de Letras do Campus do Pantanal - UFMS, Corumbá, n. 3, p. 253-272, nov. 2011.

VEÇOSSI, Criatiano Egger. O interacionismo sociodiscursivo e suas bases teóricas: Vygotsky, Saussure e Bakhtin (Volochinov). Revista Linguagens \& Cidadania, Santa Maria, v. 16, n. 1, 2014. Disponível em: https://periodicos.ufsm.br/LeC/article/view/22376/pdf. Acesso em: 24 out. 2018.

VIEIRA, Miguel Heitor Braga. Formas mínimas: minificção e literatura brasileira contemporânea. 2012. Tese (Doutorado em Letras) - Centro de Letras e Ciências Humanas, Programa de Pós-Graduação em Letras, Universidade Estadual de Londrina, Londrina, 2012.

VYGOTSKY, Levy. A mediação simbólica. In: OLIVEIRA, Marta Kohl. Vygotsky. aprendizado e desenvolvimento, um processo sócio-histórico. São Paulo: Scipione, 1997.

ZAVALA, Lauro. Seis problemas para la minificción, un género del tercer milenio: brevedad, diversidad, complicidad, fractalidad, fugacidad, virtualidad. El cuento en red, revista electrónica de teoría de la ficción breve, Ciudad del Mexico, n. 1, primavera, 2000. 